\title{
Alzheimer's Disease and Cancer: When Two Monsters Cannot Be Together
}

\author{
Shohreh Majd ${ }^{1 *}$, John Power ${ }^{1}$ and Zohreh Majd ${ }^{2}$ \\ ${ }^{1}$ Neuronal Injury and Repair Laboratory, Centre for Neuroscience, School of Medicine, Flinders University, Adelaide, SA, \\ Australia, ${ }^{2}$ Psychosomatische Tagesklinik, Passau, Germany
}

\section{OPEN ACCESS}

Edited by:

Efthimios M. C. Skoulakis,

Alexander Fleming Biomedical Sciences Research Center, Greece

Reviewed by:

Xiao-Xin Yan,

Central South University, China loannis Sotiropoulos,

University of Minho, Portugal

${ }^{*}$ Correspondence:

Shohreh Majd

shohreh.majd@flinders.edu.au

Specialty section:

This article was submitted to

Neurodegeneration,

a section of the journal

Frontiers in Neuroscience

Received: 29 June 2018

Accepted: 11 February 2019

Published: 01 March 2019

Citation:

Majd S, Power J and Majd Z

(2019) Alzheimer's Disease and Cancer: When Two Monsters

Cannot Be Together.

Front. Neurosci. 13:155.

doi: 10.3389/fnins.2019.00155
Alzheimer's disease (AD) and cancer are among the leading causes of human death around the world. While neurodegeneration is the main feature of $A D$, the most important characteristic of malignant tumors is cell proliferation, placing these two diseases in opposite sides of cell division spectrum. Interestingly, AD and cancer's pathologies consist of a remarkable common feature and that is the presence of active cell cycle in both conditions. In an in vitro model of primary adult neuronal culture, we previously showed that treating cell with beta amyloid forced neurons to start a cell cycle. Instead of cell division, however, neuronal cell cycle was aborted and a massive neurodegeneration was left behind as the consequence. A high level of cell cycle entry, which is a requirement for cancer pathogenesis, was reported in clinically diagnosed cases of $A D$, leading to neurodegeneration. The diverse clinical manifestation of a similar etiology, have puzzled researchers for many years. In fact, the evidence showed an inverse association between $A D$ and cancer prevalence, suggesting that switching pathogenesis toward AD protects patients against cancer and vice versa. In this mini review, we discussed the possibility of involvement of cell proliferation and survival dysregulation as the underlying mechanism of neurodegeneration in $A D$, and the leading event to develop both disorders' pathology. As examples, the role of phosphoinositide 3 kinase/Akt/ mammalian target of rapamycin (PI3K/Akt/mTOR) signaling pathway in cell cycle re-entry and blocking autophagy are discussed as potential common intracellular components between AD and cancer pathogenesis, with diverse clinical diagnosis.

Keywords: Alzheimer's disease, cancer, cell cycle, neurodegeneration, PI3K/Akt/mTOR, beta amyloid, tau phosphorylation, autophagy

\section{INTRODUCTION}

Aging is the main risk factor for Alzheimer's disease (AD) and cancer (White et al., 2014; Guerreiro and Bras, 2015). Although cancer can occur at any age, when it comes to a certain age category, it is not usually seen with $\mathrm{AD}$. Even a history of either of $\mathrm{AD}$ or cancer associates with a significant reduced risk of the other, suggesting that these conditions cannot usually meet each other at one time (Romero et al., 2014; Ganguli, 2015; Shi et al., 2015). The main pathological outcome of AD is a massive neurodegeneration and tissue loss throughout the brain, while cancer's pathology is based on a substantial increase in cell numbers due to an uncontrolled cell division. Understanding how pathogeneses of $\mathrm{AD}$ and cancer with a considerable number of common features such as active cell 
cycle, lead to different outcomes can open the new ways of discovering therapeutic approach for either one or both conditions.

\section{THE INVERSE ASSOCIATION BETWEEN ALZHEIMER'S DISEASE AND CANCER}

A comprehensive longitudinal study on more than one million participants revealed an inverse association between $\mathrm{AD}$ and cancer. In this study, the risk of cancer in the presence of $\mathrm{AD}$ was reduced to $50 \%$ and the risk of $\mathrm{AD}$ in individuals with cancer was decreased by 35\% (Musicco et al., 2013). The report was consistent with Roe et al. (2010) findings from another longitudinal study on 6,000 participants over 10 years (19891999). Her data demonstrated that a history of cancer decreased the risk of $\mathrm{AD}$, while $\mathrm{AD}$ prevalence was also associated with a substantial lower risk of cancer (Roe et al., 2010). Another large 15 years epidemiological study in United States, was further demonstrated a significant reduction in cancer among the patients with AD (Ganguli et al., 2005). Surprisingly, it is not only glioblastoma, the most common form of brain cancer, but other types of cancer such as cancer of lung also reduced the incidence of AD (Sanchez-Valle et al., 2017).

Although the molecular mechanism of this diversity is not clear, the high level of cell cycle activation was found to be a common pathological phenomenon between $\mathrm{AD}$ and cancer. Cancer is defined by uncontrolled repeat of cell cycle in an immortal way. On the other side, despite a progressive neurodegeneration in $\mathrm{AD}$ brains, the neurons show a substantial increase in their cell cycle related kinases (McShea et al., 2007; Chao et al., 2008; Majd et al., 2008; Moh et al., 2011; D’Angelo et al., 2017). This augmented attempt of neurons to proliferate is believed to start the neurodegenerative events, although its underlying mechanisms is still controversial.

At cellular levels, numerous pathological mechanisms are in common between AD and cancer. An example is involvement of phosphoinositide 3 kinase/Akt/ mammalian target of rapamycin (PI3K/Akt/mTOR) signaling pathway, an essential axis in cell proliferation, metabolism, growth and autophagy in pathogenesis of AD and cancer (Pei and Hugon, 2008; Morgan et al., 2009; Advani, 2010; Talbot et al., 2012; Fumarola et al., 2014; Porta et al., 2014). It is highly possible that the components of this pathway, alone or together, act as one of the common links between $\mathrm{AD}$ and cancer, in a same journey of pathogenesis but to different destinations. Identifying those links, might lead us to better therapeutic strategies.

\section{ORIGINAL HYPOTHESES OF AD ETIOLOGY: GLOWS AND GLOOMS}

For more than a century since Alois Alzheimer has introduced $\mathrm{AD}$ for the first time this disease has been recognized by two hallmarks of extracellular senile plaques and intracellular neurofibrillary tangles (NFTs) (Alzheimer, 1906; Majd et al., 2015). Glenner and Wong (1984) reveled the structure of amyloid beta peptide $(A \beta)$ as the main component of senile plaques (Glenner and Wong, 1984). This discovery led to A $\beta$ cascade hypothesis, suggesting $A \beta$ deposition as the first trigger for $\mathrm{AD}$ pathogenesis, generating the other hallmarks such as NFTs, neuro-inflammation, synaptic loss and neurodegeneration (Hardy and Selkoe, 2002; Citron, 2004). Finding mutation of amyloid precursor protein (APP) gene on chromosome 21 in many cases of familial AD (FAD) further supported this hypothesis (Goate et al., 1991). Additional investigations demonstrated that in the presence of presenilin 1 (PS1) and presenilin 2 (PS2) mutation, enhanced $A \beta$ production from APP developed the pathology in other types of FAD (LevyLahad et al., 1995; Sherrington et al., 1995). Since familial and sporadic $\mathrm{AD}$ shared the same pathological hallmarks and clinical manifestation, $A \beta$ hypothesis has been used to explain the pathogenesis in both types of AD.

Beta amyloid hypothesis, however, was challenged when the presence of senile plaques were reported in normal subjects with no clinical symptoms of AD (Dickson et al., 1992). The separate regional localization of $A \beta$ and NFT and $v$ and synaptic loss in $\mathrm{AD}$ patients, further questioned the confidence of this hypothesis (Armstrong et al., 1993; Price and Morris, 1999). Meanwhile, other studies suggested a dominant role for tauopathy as initiator of $\mathrm{AD}$ pathogenesis. Hyperphosphorylation of tau ( $\mathrm{p}$-tau), the main component of NFTs, reduces its glue-like ability in binding actin's elements to each other to build tubular structure. Instead, p-tau, clumps and builds up NFTs inside the cells (Gomez-Isla et al., 1997; Mitchell et al., 2002; Bennett et al., 2004). Copresence of NFTs, neurodegeneration and memory impairment in animal (Andorfer et al., 2005; Ramsden et al., 2005) and human studies (Maccioni et al., 2001; Ghoshal et al., 2002) and a significant correlation between p-tau in cerebrospinal fluid (CSF) and the disease progression (Kandimalla et al., 2013), supported tau hypothesis as the other explanation for AD pathology. Tau hypothesis, however, faced the same challenges as $\mathrm{A} \beta$ cascade hypothesis. The different spatial and temporal distribution of $\mathrm{A} \beta$ plaques and NFTs (Duyckaerts, 2004), along with a considerable level of neuronal death in some brain regions with no NFTs, raised the similar doubt, this time around tau hypothesis as the trigger of events in AD (de la Torre, 2008).

\section{CELL CYCLE DYSREGULATION TRIGGERS NEURODEGENERATION}

Cell cycle hypothesis has been suggested later as a trigger of $\mathrm{AD}$ pathology (Nagy, 2000; Moh et al., 2011). In general, cell cycle divides into four phases of G1 (cell growth), followed by S (DNA synthesis), G2 (cell growth) and eventually M (mitotic) phases. Progressing through different phases is mediated by cellular expression of particular proteins named cyclins and cyclindependent kinases (cdks) (Williams and Stoeber, 2012; Barnum and O'Connell, 2014). For example, G1 progression is controlled by cyclin D-cdk4, cyclin D-cdk6, and cyclin E-cdk2 (Planas-Silva and Weinberg, 1997), while cyclin A-cdk2 and cyclin B-cdk1 derive cell progression through G2 and entering into $M$ phase (Nigg, 2001). 
Many of these cdks were found elevated in AD neurons, which is an unusual finding for the cells that are considered as post mitotic cells. Although premature neurons experience cell cycle at the beginning of their life in order to differentiate to neurons, they permanently remained in a quiescent state after that for the rest of their life (Lopes et al., 2009). The reason behind this lasting exit from the cell cycle is still a mystery, although the fact that brain tumors have mainly the astrocytes or oligodendrocytes origins but not neuronal origin strongly supports the fact of neuronal inability to divide (Liu and Zong, 2012).

In some circumstances, cell cycle re-entry in adult neurons (from G0 to G1) is followed by cell cycle arrest in an early stage (before G1/S transition point), when re-differentiation is still possible. This transient re-entry into cell cycle in healthy brain might be a part of synaptic remodeling (Arendt, 2003), however, in a large scale, it mainly occurs as a result of insults such as oxidative stress, cytotoxicity or deprivation of neurotrophic factors (Klein and Ackerman, 2003; Kruman, 2004; Chen et al., 2013). Under any of these stress conditions, the control mechanism on G1 to S phase progression fails and cell cycle progression is usually aborted before new DNA synthesis (Liu and Greene, 2001; Becker and Bonni, 2004). Some neurons, however, escape this abortion and enter into $\mathrm{S}$ phase, replicate their DNA (Yang et al., 2001; Bonda et al., 2009) and subsequently enter to G2 phase (Nagy et al., 1998; Zhu et al., 2004).

Arriving at G2 phase is the farthest stage that neurons can reach. Why cell division never occurs in mature neurons is still poorly understood, however, a non-canonical pathway of DNA replication, mediated by DNA polymerase $\beta$ has been suggested as the possible explanation.

It has been shown that degenerative neurons of hippocampal and basal forebrain areas of $\mathrm{AD}$ brains have replicated their DNA, either completely or partially. This evidence proved that DNA replication occurs in neuronal cells of affected areas of AD brains, with no similar phenomenon in unaffected regions of the $\mathrm{AD}$ brain or in non-demented age-matched subjects (Yang and Herrup, 2007). The cells, however, are largely unable to progress further to complete their division. One likely reason could be the faulty replicated DNA as a result of dominant action of DNA polymerase $\beta$ in mature neurons.

While in the other cell types DNA polymerase $\alpha, \gamma$, or $\varepsilon$ are in charge of DNA replication, in neurons polymerase $\beta$ partially finalizes this process.

The expression of DNA polymerase $\beta$, an error-prone enzyme is frequently over-regulated in AD brains, which is accompanied with the over-expression of proliferating cell nuclear antigen (PCNA) (Zhang et al., 2014). Due to polymerase $\beta$ error-prone activity replicated DNA contains a few errors. Supercoiling and catenation of duplicated DNA along with the lack of topoisomerase 2, required for successful decatenation and segregation of daughter loops after DNA replication is another reason for inability of neurons to divide (Tiwari et al., 2012; Aranda-Anzaldo and Dent, 2017).

The damaged DNA and unsegregated (catenated) replicons lead the cells to apoptosis (Herrup et al., 2004), however, it is possible that before apoptosis occurs, the neurons remain in a permissive phase of G2 phase for a while. Some studies hypothesize that additional further insults (protein aggregation) is needed for the final progressing of the neurons to death (Yang and Herrup, 2007). This hypothesis was further approved by showing the activation of some cellular mechanisms in G2 phase, deriving the formation of NFTs and A $\beta$ plaques (Baumann et al., 1993; Currais et al., 2009) in apoptosis incompetent neurons. These include a significant increase in APP phosphorylation at $\mathrm{Thr}^{668}$ by $\mathrm{cdk} 2$, cdk4, and cdk5, which increases its beta-amyloid production and APP proteolysis by the activated caspases during cell cycle (Liu et al., 2003; Chong et al., 2005; Judge et al., 2011; Folch et al., 2012). Overall, abnormal re-entry into the cell cycle is thought to initiate the pathway resulting in NFTs, apoptotic avoidance, and A $\beta$ production (Yang et al., 2003; McShea et al., 2007; Chen et al., 2010).

\section{Cell Cycle in Cancer}

Cell cycle entry is the essential mechanism to develop cancer pathology. Although the majority of the cells either permanently live in a post mitotic status such as neurons or myocytes, or are temporarily withdrawn from it such as glial cells or hepatocytes, a minor group of cells such as epithelial cells are often being into an active phase of proliferation (Williams and Stoeber, 2012). At the checkpoints between cell cycle phases, the transition is tightly regulated besides a close monitoring of genome accuracy (Hartwell and Weinert, 1989; Stumpf et al., 2013; Visconti et al., 2016). Failing to repair DNA damage could end up to apoptosis or persistent genomic abnormality, while repeating this defect in DNA replication leads to cancer pathology, presented by uncontrolled cycles of cell division (Broustas and Lieberman, 2014).

Revealing cell cycle involvement in pathogenesis of both $\mathrm{AD}$ and cancer, suggested the same response to some triggers with a possible similar nature. Oxidative stress is widely shown in AD brains (Majd and Power, 2018) and along with metabolic stress, they can be considered as the triggers to initiate cell cycle and developing $\mathrm{AD}$ and cancer pathology (Moreira et al., 2010; Sun et al., 2016). The outcome, however, is different in response to a similar trigger. While in $\mathrm{AD}$ cell cycle re-entry triggers developing $\mathrm{AD}$ hallmarks and neuronal death instead of neuronal proliferation (Liu and Greene, 2001; Becker and Bonni, 2004), in cancer cell death is replaced by unlimited cell division (Broustas and Lieberman, 2014). Given the importance of mitotic mechanisms in $\mathrm{AD}$ and cancer, determining the common triggers that stimulate cell cycles' initiation in both conditions seems critical. Here we discuss the possible involvement of the PI3K/Akt/mTOR pathway as one of the triggers in the pathophysiology of cancer and $\mathrm{AD}$, in relation to cell cycle.

\section{PI3 KINASE/Akt/mTOR PATHWAY IN ALZHEIMER'S DISEASE AND CANCER}

The PI3K/Akt signaling pathway has a critical regulatory role in cellular growth, proliferation, survival and apoptosis ( $\mathrm{Yu}$ and Cui, 2016). The main downstream target of PI3K and 
Akt is mTOR, a peptide with serine/threonine kinase activity. mTOR is a member of PI3K-related kinase (PIKK) family that specifically coordinates cell growth and cell division, by controlling cell cycle progression through different phases (Vadlakonda et al., 2013).

The mTOR peptide is made of two subunits. mTORC1 that is activated by growth factors, nutrients and energy signals, while mTORC2 is less sensitive to energy status and mainly regulates the actin cytoskeleton through its stimulatory impact on PKC- $\alpha$ and Akt (Moschetta et al., 2014). While mTOR constantly monitors oxygen, nutrient and mitogenic signals' availability (Liu et al., 2009; Zhou and Huang, 2011), its activation is highly regulated by PI3K and Akt (Populo et al., 2012). Interestingly, hyperactivation of PI3K/Akt pathway is often associated with cancer progression (Morgan et al., 2009; Advani, 2010; Fumarola et al., 2014; Porta et al., 2014) and surprisingly contributes to $\mathrm{AD}$ pathology during aging (Pei and Hugon, 2008; Talbot et al., 2012).

In animal and cell culture studies dysregulation of PI3K, Akt, and mTOR (Rodon et al., 2013) was led to tumor formation, while knocking out of PI3K, Akt, or mTOR, blocked this oncogenic transformation (Liu et al., 2009), inhibited tumor growth and blocked its invasiveness (Cheng et al., 2005; Slomovitz and Coleman, 2012; Statz et al., 2017). PI3K/Akt/mTOR contribution to $\mathrm{AD}$ pathology was demonstrated by numerous evidence (O’Neill, 2013). Activated mTOR is a common finding in AD brains, a possible explanation for cell cycle re-entry in $\mathrm{AD}$ (Webber et al., 2005; Bhaskar et al., 2009; Lee et al., 2009; Arendt, 2012; Counts and Mufson, 2017). The role of activated mTOR as a cellular driving force to start proliferation suggests the contribution of mTOR in cell cycle re-entry pathogenesis of $\mathrm{AD}$ (Norambuena et al., 2017). mTOR is also believed to increase tau-induced neurodegeneration in a cell cycle-dependent manner (Rogaeva et al., 2006), under the original driving force which could be energy stress as the initiator of abnormal cell cycles (Wen et al., 2004).

\section{PI3K/Akt/mTOR AND AUTOPHAGY: ANOTHER COMMON PATHOLOGICAL MECHANISM IN AD AND CANCER}

$\mathrm{PI} 3 \mathrm{~K} / \mathrm{Akt} / \mathrm{mTOR}$ role in cell cycle initiation is not the only shared pathological mechanism between $\mathrm{AD}$ and cancer, underlying neurodegeneration in $\mathrm{AD}$. Activation of mTOR has a negative impact on autophagy, a cytoprotective mechanism to clear toxic proteins such as $A \beta$. While enhanced autophagy due to mTOR inhibition reduces the aggregation of misfolded proteins and delays neurodegeneration in a wide range of neurodegenerative disorders (Ravikumar et al., 2002; Spencer et al., 2009), enhanced mTOR signaling contributes to inhibition of autophagy, deposition of toxic peptides and progressive neurodegeneration.

Preclinical research evidence supports that mTOR in conjunction with PI3K/Akt pathway regulates autophagy, a mechanism that could assist the body to remove malignant cells in cancer, and clear toxic proteins in $\mathrm{AD}$

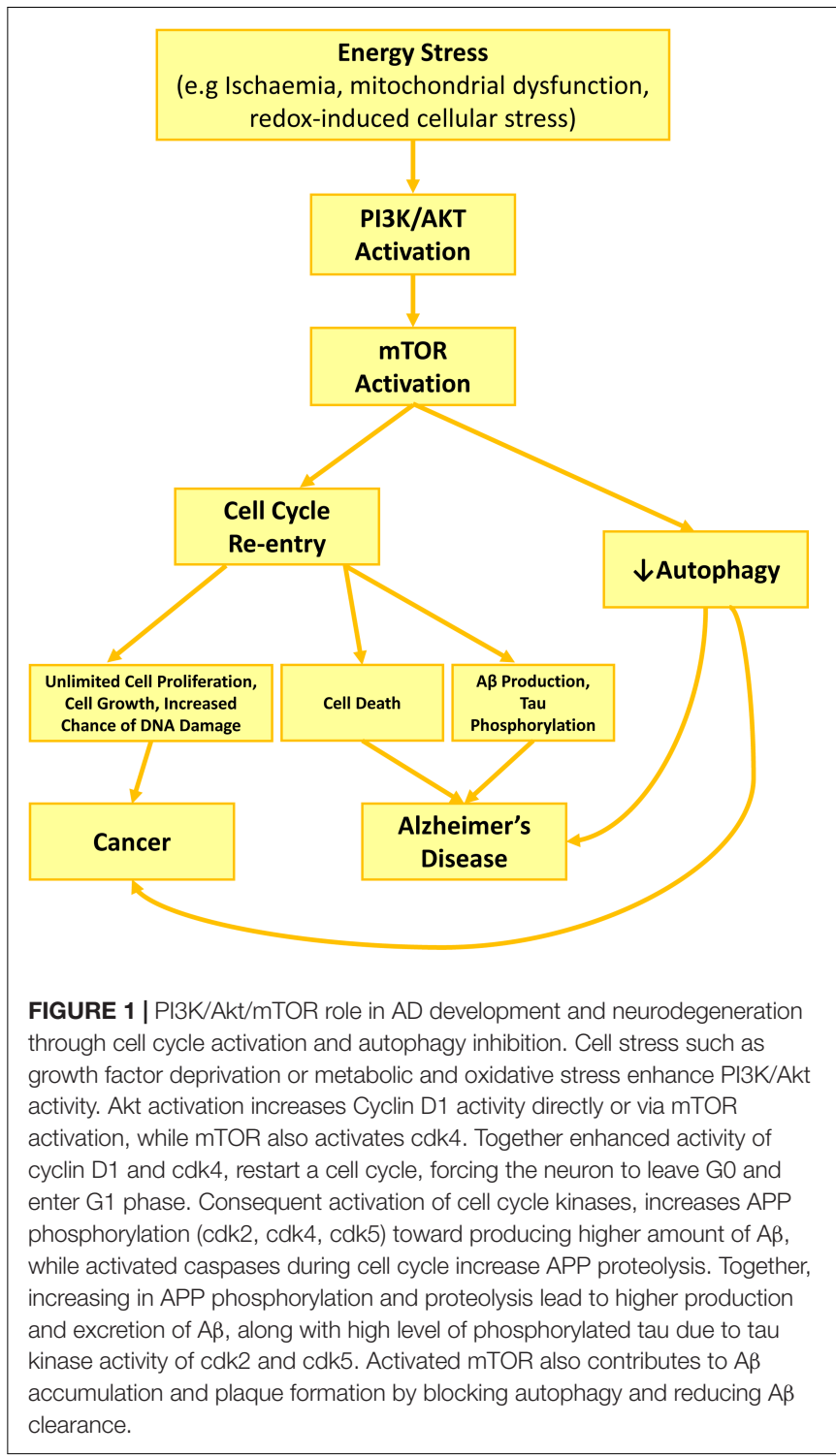

(Heras-Sandoval et al., 2014). The failure of brain in autophagy and clearing aggregated proteins is one of contributing factors in AD pathology (Bhaskar et al., 2009; Spilman et al., 2010; Li et al., 2013; Pierce et al., 2013). Increase in $A \beta$ deposition (Chen et al., 2009; Cai et al., 2012), decrease its clearance (Pei and Hugon, 2008; Cai et al., 2012), disrupted clearance of tau and the consequent synaptic loss and cognitive decline in $\mathrm{AD}$, all could occur as the result of PI3K/Akt/mTOR activation (Ma et al., 2011; Graziotto et al., 2012; O’Neill, 2013; Yang et al., 2013). A positive impact of mTOR inhibitors in inducing autophagy, increasing $A \beta$ clearance and lessening $A \beta$ aggregation was previously documented (Spilman et al., 2010). Reduced autophagy is also a common pathological finding in cancer (Chang et al., 2012; Cui et al., 2013). Several studies proposed that inhibition of $\mathrm{PI} 3 \mathrm{~K} / \mathrm{Akt} / \mathrm{mTOR}$ pathway increased autophagy and effectively reduced the tumor outgrowth (Ji et al., 2015; 

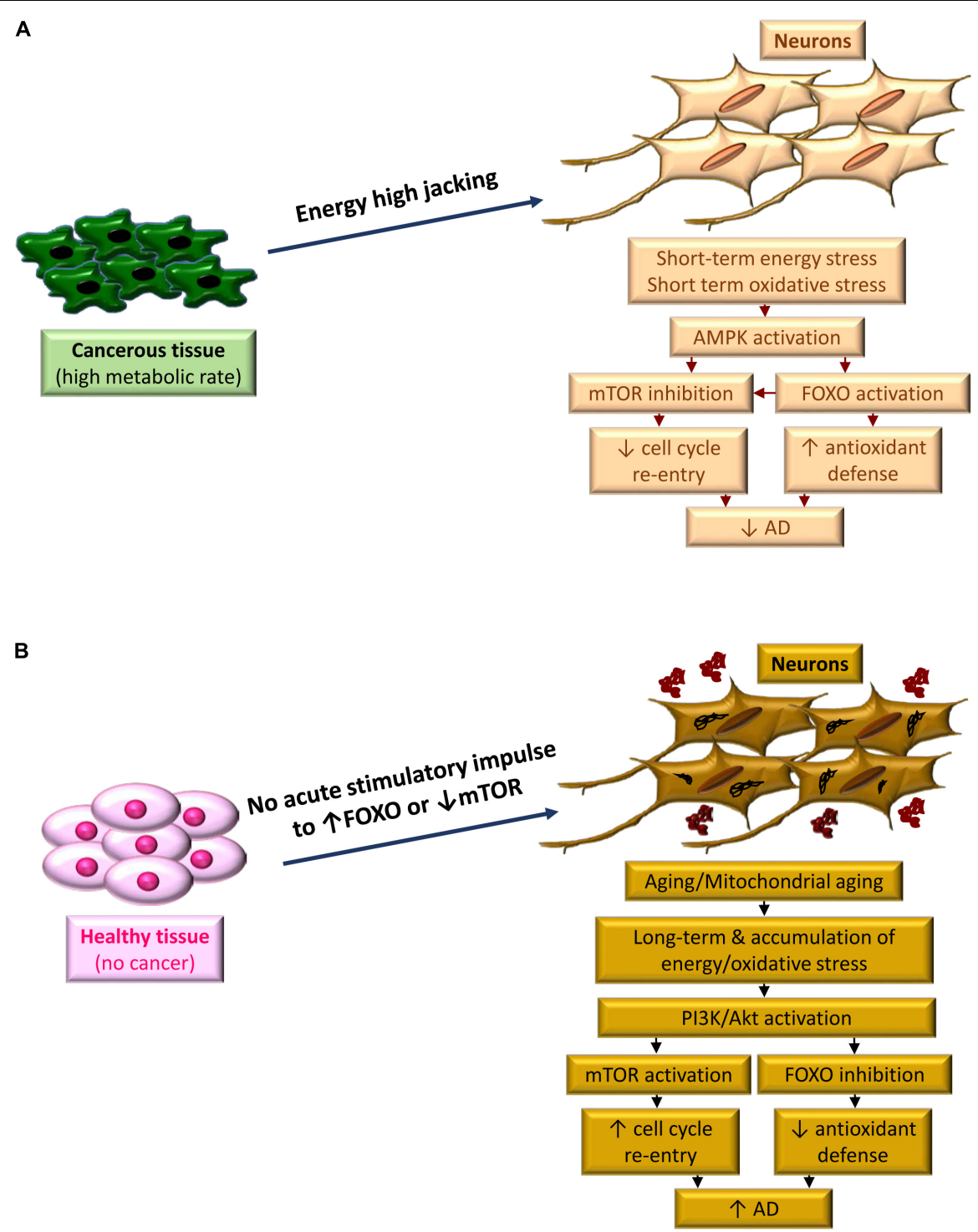

FIGURE 2 | The period of metabolic stress, defines the fate between cancer and AD. (A) High metabolic demand of cancerous tissue high jacks energy from highly energy demanded neurons. Acute condition of inadequate supply of energy and concurrent oxidative stress activates AMPK, leading to FOXO activation and m-TOR inhibition. A bust in antioxidant defense occurs along with blocking cell cycle re-entry due to FOXO activation and mTOR inhibition, respectively, which reduces the risk of AD development. (B) In the absence of cancer, the acute signal to boost the antioxidant defense of neurons does not exist. Instead, due to aging the neurons, which are facing mitochondrial aging, experience a chronic oxidative stress. This is due to chronic effect of energy stress and accumulation of oxidative damage. Activation of PI3K/AKt pathways dominantly occurs as a protective response, however, this activation leads to further FOXO inhibition and m-TOR activation. Consequently, cell cycle re-entry along with reduced expression of antioxidant enzymes result in progressing of AD pathology.

Butler et al., 2017). Thus, tumorigenesis is promoted when autophagy is compromised.

\section{A COMMON TRIGGER FOR NEURODEGENERATION AND CANCER}

Hyperactivation of PI3K/Akt/mTOR under cell stress conditions could be a mechanism underlying neurodegeneration in $\mathrm{AD}$ (Figure 1). Although under cellular stress, PI3K/Akt/mTOR acts as one of the major regulators of cell survival
(Datta et al., 1999), its constant activation affect the cells in a negative manner. The repetitive metabolic stress is a shared phenomenon for both $\mathrm{AD}$ and cancer (Moreira et al., 2010; Morgen and Frolich, 2015; Sun et al., 2016; Zhao et al., 2017), which could trigger PI3K/Akt/mTOR activation, cell cycle re-entry and autophagy inhibition, the other three shared features between $\mathrm{AD}$ and cancer.

Activation of PI3K/Akt/mTOR pathway is a cellular response to metabolic stress in order to promote survival ( $\mathrm{Yu}$ and Cui, 2016). Phosphorylated PI3K and Akt, during energy stress situation such as mitochondrial stress enhance survival and 


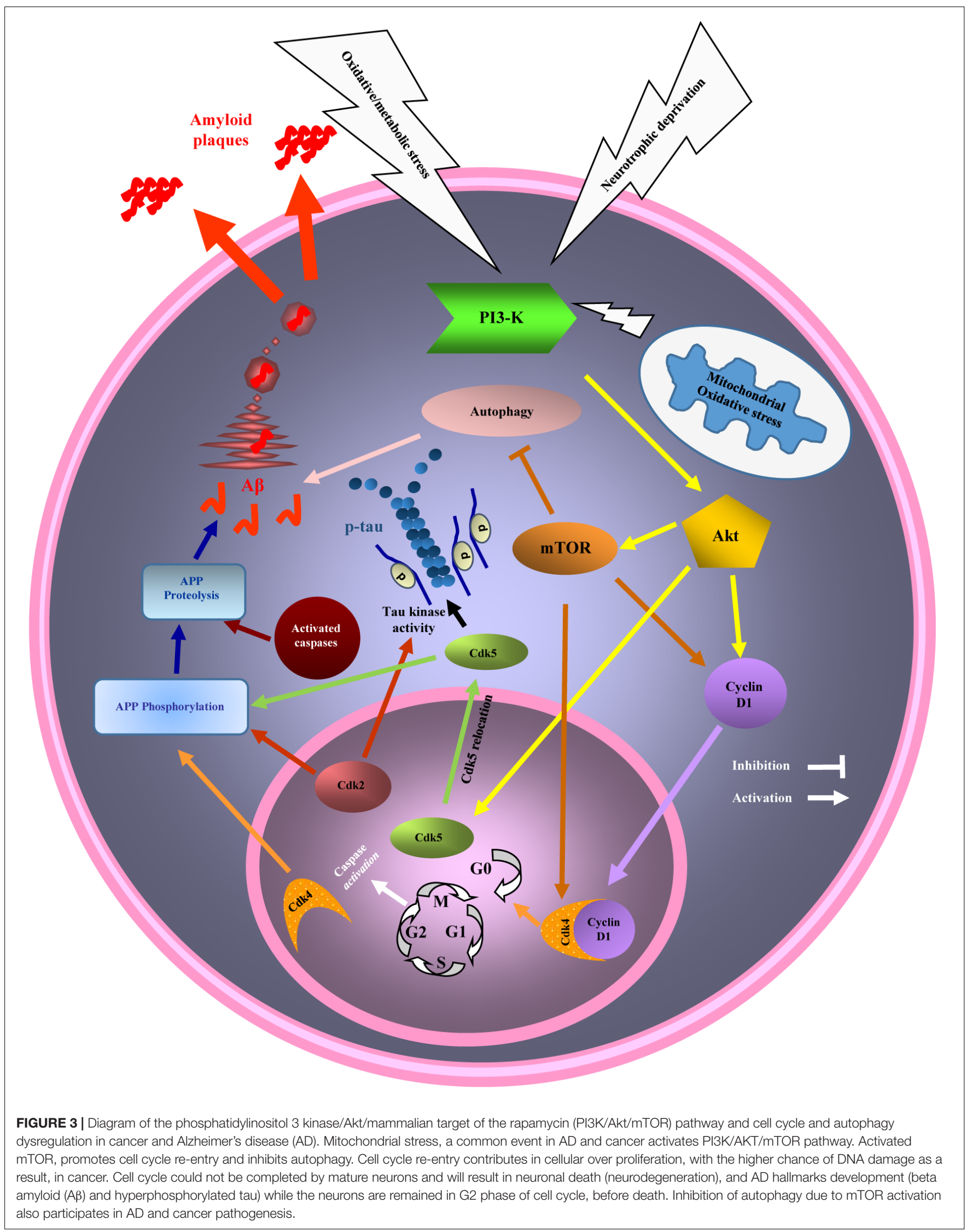


inhibits apoptosis. To reduce the burden of metabolic pressure on cells, enhanced oxidative phosphorylation occurs through phosphorylation of downstream proteins in an Akt-dependent manner. This strategy to protect the cells against energy stress, however, costs the cells. Activation of Akt inhibits the activity of a few transcription factors such as FoxO that are in charge of regulating the expression of antioxidant enzymes such as superoxide dismutase, while at the same time it activates mTOR (Yang et al., 2017). Consequently, the reduction in antioxidant enzymes expression result in oxidative stress, while the activated mTOR forces the cells into cell cycle and inhibits autophagy. The consequences will be cell cycle progression and autophagy inhibition. Altogether, the activation of cell survival pathway due to energy stress may rescue the cells temporary; however, the long-term consequence could initiate or develop either $\mathrm{AD}$ or cancer pathology.

\section{THE IMPACT OF CHRONIC STRESS ON AD AND CANCER PATHOGENESIS}

A wide range of evidence suggests a strong link between the constant elevation in stress-related hormones including glucocorticoids and epinephrine and development of $\mathrm{AD}$ hallmarks such as p-tau and A $\beta$ (Green et al., 2006; Catania et al., 2009; Sotiropoulos et al., 2011; Dioli et al., 2017). It is believed that stress not only associates with misprocessing of $\mathrm{APP}$, leading to $\mathrm{A} \beta$ plaques formation, but it interrupts the process of normal autophagy, which results in further buildup of intracellular $p$-tau and extracellular $A \beta$ accumulation (Silva et al., 2018). Interestingly, chronic stress also associates with a higher risk of cancer development (Cui et al., 2019). Interestingly, $\mathrm{PI} 3 \mathrm{~K} / \mathrm{Akt} / \mathrm{mTOR}$ acts as a cross point between $\mathrm{AD}$ and cancer, as this pathway is activated under the influence of stress-related hormones, causing cell proliferation and autophagy reduction (Silva et al., 2018; Cui et al., 2019). While PI3K/Akt/mTOR can be considered as a stress-dependent overlapped pathway between $\mathrm{AD}$ and cancer, future studies are still required to elucidate the further details, linking stress-related hormones to PI3K/Akt/mTOR dysregulation.

\section{THE PERIOD AND SEVERITY OF ENERGY STRESS SAY THE FINAL WORD}

While cell stress could be the common trigger for both $\mathrm{AD}$ and cancer, the severity of energy stress and the duration that the subject is affected by, seem to be the decision maker in choosing between the two monsters. Compare to $\mathrm{AD}$, which develops within 20 years, cancer could be considered as an acute pathological condition. Uncontrolled cell cycle re-entry in a malignant tissue puts the entire body in a sudden starving situation due to shifting the metabolic resources to affected tissue (Li et al., 2014). Among all the tissues, the brain neurons are the most susceptible cells to suffer from this imbalance between their high metabolic needs and the lack of the proper supply of energy, leading to reactive oxygen species (ROS) accumulation and oxidative damage. This activates a family of FOXO proteins in order to increase the expression of antioxidant enzymes as a protective mechanism to reduce the damage (Hay, 2011; Gomez-Crisostomo et al., 2014). One of the examples is adenosine monophosphate protein kinase protein (AMPK)dependent FOXO3 activation under metabolic stress (Greer et al., 2007), while mTOR and consequently cell cycle re-entry is also inhibited by AMPK (Xu et al., 2012). Activation of FOXO itself also inhibits mTOR pathway, putting an additional halt on neuronal cell cycle re-entry (Lin et al., 2014). This acute response may override the neuronal PI3K/Akt/mTOR activation (Hay, 2011), with the goal of reducing energy stress and oxidative damage, until the patient either dies or survives from the cancer. In survived patients, this protective response of the brain could provide the subject with a higher level of antioxidant enzymes, less chance for cell cycle re-entry and better protection against $\mathrm{AD}$, at least for a while, compare to normal individuals.

For the people with $\mathrm{AD}$ who show less prevalence of cancer, energy and oxidative stress are not an acute but a chronic phenomenon, associated with mitochondrial aging and accumulated ROS during decades. Depriving from the acute stimulatory effect of cancer on the FOXO machinery and mTOR inhibition in neurons, these cells will gather the accumulated oxidative damage, and higher possibility to restart a cell cycle, within the years. That can lead to the domination of PI3K/Akt/mTOR pathway, Akt-dependent inactivation of FOXO3 (Santo et al., 2013), cell cycle re-entry and AD hallmarks development within a long period of almost 20 years (Figure 2).

\section{CONCLUSION}

In conclusion, deregulation of cell cycle as a result of $\mathrm{PI} 3 \mathrm{~K} / \mathrm{Akt} / \mathrm{mTOR}$ pathway activation can be considered as a trigger for neurodegeneration in $\mathrm{AD}$ and explains the overlapped pathogenesis between $\mathrm{AD}$ and cancer with a diverse destiny. The common pathological mechanism that leads to cell growth or survival and cell proliferation in cancer but to a massive cell death in $\mathrm{AD}$ could explain inverse association between these diseases (Figure 3). Although many other aspects of a possible explanation for $\mathrm{AD}$ neurodegeneration and pathological link connecting $\mathrm{AD}$ and cancer are remained to be clarified, cell cycle-related mechanism seems to have a major role in $\mathrm{AD}$ and cancer development. Further understanding of this mechanism may open the novel ways to discover therapeutic strategies for either situations or both.

\section{AUTHOR CONTRIBUTIONS}

All authors were involved in the writing and revising the manuscript.

\section{ACKNOWLEDGMENTS}

The authors would like to thank Dr. Timothy Chataway from proteomics laboratory of Flinders University for his enthusiastic support. 


\section{REFERENCES}

Advani, S. H. (2010). Targeting mTOR pathway: a new concept in cancer therapy. Indian J. Med. Paediatr. Oncol. 31, 132-136. doi: 10.4103/0971-5851.76197

Alzheimer (1906). Über einen eigenartigen schweren Erkrankungsproze $\beta$ der Hirnrincle. Neurol. Central 25:1134.

Andorfer, C., Acker, C. M., Kress, Y., Hof, P. R., Duff, K., and Davies, P. (2005). Cell-cycle reentry and cell death in transgenic mice expressing nonmutant human tau isoforms. J. Neurosci. 25, 5446-5454. doi: 10.1523/jneurosci.463704.2005

Aranda-Anzaldo, A., and Dent, M. A. (2017). Why cortical neurons cannot divide, and Why do they usually die in the attempt? J. Neurosci. Res. 95, 921-929. doi: $10.1002 /$ jnr.23765

Arendt, T. (2003). Synaptic plasticity and cell cycle activation in neurons are alternative effector pathways: the 'Dr. Jekyll and Mr. Hyde concept' of Alzheimer's disease or the yin and yang of neuroplasticity. Prog. Neurobiol. 71, 83-248.

Arendt, T. (2012). Cell cycle activation and aneuploid neurons in Alzheimer's disease. Mol. Neurobiol. 46, 125-135. doi: 10.1007/s12035-012-8262-0

Armstrong, R. A., Myers, D., and Smith, C. U. (1993). The spatial patterns of beta/A4 deposit subtypes in Alzheimer's disease. Acta Neuropathol. 86, 36-41.

Barnum, K. J., and O'Connell, M. J. (2014). Cell cycle regulation by checkpoints. Methods Mol. Biol. 1170, 29-40. doi: 10.1007/978-1-4939-0888-2_2

Baumann, K., Mandelkow, E. M., Biernat, J., Piwnica-Worms, H., and Mandelkow, E. (1993). Abnormal Alzheimer-like phosphorylation of tauprotein by cyclin-dependent kinases cdk2 and cdk5. FEBS Lett. 336, 417-424.

Becker, E. B., and Bonni, A. (2004). Cell cycle regulation of neuronal apoptosis in development and disease. Prog. Neurobiol. 72, 1-25. doi: 10.1016/j.pneurobio. 2003.12.005

Bennett, D. A., Schneider, J. A., Wilson, R. S., Bienias, J. L., and Arnold, S. E. (2004). Neurofibrillary tangles mediate the association of amyloid load with clinical Alzheimer disease and level of cognitive function. Arch. Neurol. 61, 378-384. doi: 10.1001/archneur.61.3.378

Bhaskar, K., Miller, M., Chludzinski, A., Herrup, K., Zagorski, M., and Lamb, B. T. (2009). The PI3K-Akt-mTOR pathway regulates Abeta oligomer induced neuronal cell cycle events. Mol. Neurodegener. 4:14. doi: 10.1186/1750-13 26-4-14

Bonda, D. J., Evans, T. A., Santocanale, C., Llosa, J. C., Vina, J., Bajic, V., et al. (2009). Evidence for the progression through S-phase in the ectopic cell cycle reentry of neurons in Alzheimer disease. Aging 1, 382-388. doi: 10.18632/aging. 100044

Broustas, C. G., and Lieberman, H. B. (2014). DNA damage response genes and the development of cancer metastasis. Radiat. Res. 181, 111-130. doi: 10.1667/ rr13515.1

Butler, D. E., Marlein, C., Walker, H. F., Frame, F. M., Mann, V. M., Simms, M. S., et al. (2017). Inhibition of the PI3K/AKT/mTOR pathway activates autophagy and compensatory Ras/Raf/MEK/ERK signalling in prostate cancer. Oncotarget 8, 56698-56713. doi: 10.18632/oncotarget.18082

Cai, Z., Zhao, B., Li, K., Zhang, L., Li, C., Quazi, S. H., et al. (2012). Mammalian target of rapamycin: a valid therapeutic target through the autophagy pathway for Alzheimer's disease? J. Neurosci. Res. 90, 1105-1118. doi: 10.1002/jnr.23011

Catania, C., Sotiropoulos, I., Silva, R., Onofri, C., Breen, K. C., Sousa, N., et al. (2009). The amyloidogenic potential and behavioral correlates of stress. Mol. Psychiatry 14, 95-105. doi: 10.1038/sj.mp.4002101

Chang, Y., Lin, J., and Tsung, A. (2012). Manipulation of autophagy by MIR375 generates antitumor effects in liver cancer. Autophagy 8, 1833-1834.

Chao, D. L., Sanchez, C. A., Galipeau, P. C., Blount, P. L., Paulson, T. G., Cowan, D. S., et al. (2008). Cell proliferation, cell cycle abnormalities, and cancer outcome in patients with Barrett's esophagus: a long-term prospective study. Clin. Cancer Res. 14, 6988-6995. doi: 10.1158/1078-0432.ccr-07-5063

Chen, J., Cohen, M. L., Lerner, A. J., Yang, Y., and Herrup, K. (2010). DNA damage and cell cycle events implicate cerebellar dentate nucleus neurons as targets of Alzheimer's disease. Mol. Neurodegener. 5:60. doi: 10.1186/1750-13 26-5-60

Chen, M. J., Ng, J. M., Peng, Z. F., Manikandan, J., Yap, Y. W., Llanos, R. M., et al. (2013). Gene profiling identifies commonalities in neuronal pathways in excitotoxicity: evidence favouring cell cycle re-activation in concert with oxidative stress. Neurochem. Int. 62, 719-730. doi: 10.1016/j.neuint.2012.12.015
Chen, T. J., Wang, D. C., and Chen, S. S. (2009). Amyloid-beta interrupts the PI3K-Akt-mTOR signaling pathway that could be involved in brain-derived neurotrophic factor-induced Arc expression in rat cortical neurons. J. Neurosci. Res. 87, 2297-2307. doi: 10.1002/jnr.22057

Cheng, J. Q., Lindsley, C. W., Cheng, G. Z., Yang, H., and Nicosia, S. V. (2005). The Akt/PKB pathway: molecular target for cancer drug discovery. Oncogene 24, 7482-7492. doi: 10.1038/sj.onc. 1209088

Chong, Z. Z., Li, F., and Maiese, K. (2005). Employing new cellular therapeutic targets for Alzheimer's disease: a change for the better? Curr. Neurovasc. Res. 2, 55-72.

Citron, M. (2004). Strategies for disease modification in Alzheimer's disease. Nat. Rev. Neurosci. 5, 677-685. doi: 10.1038/nrn1495

Counts, S. E., and Mufson, E. J. (2017). Regulator of Cell Cycle (RGCC) expression during the progression of Alzheimer's disease. Cell Transpl. 26, 693-702. doi: $10.3727 / 096368916 \times 694184$

Cui, B., Luo, Y., Tian, P., Peng, F., Lu, J., Yang, Y., et al. (2019). Stress-induced epinephrine enhances lactate dehydrogenase $\mathrm{A}$ and promotes breast cancer stem-like cells. J Clin Invest doi: 10.1172/jci121685 [Epub ahead of print].

Cui, J., Gong, Z., and Shen, H. M. (2013). The role of autophagy in liver cancer: molecular mechanisms and potential therapeutic targets. Biochim. Biophys. Acta 1836, 15-26. doi: 10.1016/j.bbcan.2013.02.003

Currais, A., Hortobagyi, T., and Soriano, S. (2009). The neuronal cell cycle as a mechanism of pathogenesis in Alzheimer's disease. Aging 1, 363-371. doi: 10.18632/aging.100045

D’Angelo, B., Astarita, C., Boffo, S., Massaro-Giordano, M., Iannuzzi, C., Caporaso, A., et al. (2017). LPS-induced inflammatory response triggers cell cycle reactivation in murine neuronal cells through retinoblastoma proteins induction. Cell Cycle 16, 2330-2336. doi: 10.1080/15384101.2017.1363943

Datta, S. R., Brunet, A., and Greenberg, M. E. (1999). Cellular survival: a play in three Akts. Genes Dev. 13, 2905-2927.

de la Torre, J. C. (2008). Pathophysiology of neuronal energy crisis in Alzheimer's disease. Neurodegener. Dis. 5, 126-132. doi: 10.1159/000113681

Dickson, D. W., Crystal, H. A., Mattiace, L. A., Masur, D. M., Blau, A. D., Davies, P., et al. (1992). Identification of normal and pathological aging in prospectively studied nondemented elderly humans. Neurobiol. Aging 13, 179-189.

Dioli, C., Patricio, P., Trindade, R., Pinto, L. G., Silva, J. M., Morais, M., et al. (2017). Tau-dependent suppression of adult neurogenesis in the stressed hippocampus. Mol. Psychiatry 22, 1110-1118. doi: 10.1038/mp.2017.103

Duyckaerts, C. (2004). Looking for the link between plaques and tangles. Neurobiol Aging 25, 735-739; discussion 743-736. doi: 10.1016/j.neurobiolaging.2003. 12.014

Folch, J., Junyent, F., Verdaguer, E., Auladell, C., Pizarro, J. G., Beas-Zarate, C., et al. (2012). Role of cell cycle re-entry in neurons: a common apoptotic mechanism of neuronal cell death. Neurotox Res. 22, 195-207. doi: 10.1007/s12640-0119277-4

Fumarola, C., Bonelli, M. A., Petronini, P. G., and Alfieri, R. R. (2014). Targeting $\mathrm{PI} 3 \mathrm{~K} / \mathrm{AKT} / \mathrm{mTOR}$ pathway in non small cell lung cancer. Biochem. Pharmacol. 90, 197-207. doi: 10.1016/j.bcp.2014.05.011

Ganguli, M. (2015). Cancer and dementia: it's complicated. Alzheimer Dis. Assoc. Disord. 29, 177-182. doi: 10.1097/wad.0000000000000086

Ganguli, M., Dodge, H. H., Shen, C., Pandav, R. S., and Dekosky, S. T. (2005). Alzheimer disease and mortality: a 15-year epidemiological study. Arch. Neurol. 62, 779-784. doi: 10.1001/archneur.62.5.779

Ghoshal, N., Garcia-Sierra, F., Wuu, J., Leurgans, S., Bennett, D. A., Berry, R. W., et al. (2002). Tau conformational changes correspond to impairments of episodic memory in mild cognitive impairment and Alzheimer's disease. Exp. Neurol. 177, 475-493.

Glenner, G. G., and Wong, C. W. (1984). Alzheimer's disease: initial report of the purification and characterization of a novel cerebrovascular amyloid protein. Biochem. Biophys. Res. Commun. 120, 885-890.

Goate, A., Chartier-Harlin, M. C., Mullan, M., Brown, J., Crawford, F., Fidani, L., et al. (1991). Segregation of a missense mutation in the amyloid precursor protein gene with familial Alzheimer's disease. Nature 349, 704-706. doi: 10. 1038/349704a0

Gomez-Crisostomo, N. P., Rodriguez Martinez, E., and Rivas-Arancibia, S. (2014). Oxidative stress activates the transcription factors FoxO 1a and FoxO $3 \mathrm{a}$ in the hippocampus of rats exposed to low doses of ozone. Oxid. Med. Cell Longev. 2014:805764. doi: 10.1155/2014/805764 
Gomez-Isla, T., Hollister, R., West, H., Mui, S., Growdon, J. H., Petersen, R. C., et al. (1997). Neuronal loss correlates with but exceeds neurofibrillary tangles in Alzheimer's disease. Ann. Neurol. 41, 17-24. doi: 10.1002/ana.410410106

Graziotto, J. J., Cao, K., Collins, F. S., and Krainc, D. (2012). Rapamycin activates autophagy in Hutchinson-Gilford progeria syndrome: implications for normal aging and age-dependent neurodegenerative disorders. Autophagy 8, 147-151. doi: $10.4161 /$ auto.8.1.18331

Green, K. N., Billings, L. M., Roozendaal, B., Mcgaugh, J. L., and Laferla, F. M. (2006). Glucocorticoids increase amyloid-beta and tau pathology in a mouse model of Alzheimer's disease. J. Neurosci. 26, 9047-9056. doi: 10.1523/jneurosci. 2797-06.2006

Greer, E. L., Oskoui, P. R., Banko, M. R., Maniar, J. M., Gygi, M. P., Gygi, S. P., et al. (2007). The energy sensor AMP-activated protein kinase directly regulates the mammalian FOXO3 transcription factor. J. Biol. Chem. 282, 30107-30119. doi: 10.1074/jbc.M705325200

Guerreiro, R., and Bras, J. (2015). The age factor in Alzheimer's disease. Genome Med. 7:106. doi: 10.1186/s13073-015-0232-5

Hardy, J., and Selkoe, D. J. (2002). The amyloid hypothesis of Alzheimer's disease: progress and problems on the road to therapeutics. Science 297, 353-356. doi: $10.1126 /$ science. 1072994

Hartwell, L. H., and Weinert, T. A. (1989). Checkpoints: controls that ensure the order of cell cycle events. Science 246, 629-634.

Hay, N. (2011). Interplay between FOXO, TOR, and Akt. Biochim. Biophys. Acta 1813, 1965-1970. doi: 10.1016/j.bbamcr.2011.03.013

Heras-Sandoval, D., Perez-Rojas, J. M., Hernandez-Damian, J., and PedrazaChaverri, J. (2014). The role of PI3K/AKT/mTOR pathway in the modulation of autophagy and the clearance of protein aggregates in neurodegeneration. Cell Signal 26, 2694-2701. doi: 10.1016/j.cellsig.2014.08.019

Herrup, K., Neve, R., Ackerman, S. L., and Copani, A. (2004). Divide and die: cell cycle events as triggers of nerve cell death. J. Neurosci. 24, 9232-9239. doi: 10.1523/jneurosci.3347-04.2004

Ji, Y., Di, W., Yang, Q., Lu, Z., Cai, W., and Wu, J. (2015). Inhibition of autophagy increases proliferation inhibition and apoptosis induced by the PI3K/mTOR Inhibitor NVP-BEZ235 in breast cancer cells. Clin. Lab. 61, 1043-1051.

Judge, M., Hornbeck, L., Potter, H., and Padmanabhan, J. (2011). Mitosis-specific phosphorylation of amyloid precursor protein at threonine 668 leads to its altered processing and association with centrosomes. Mol. Neurodegener. 6:80. doi: 10.1186/1750-1326-6-80

Kandimalla, R. J., Prabhakar, S., Wani, W. Y., Kaushal, A., Gupta, N., Sharma, D. R., et al. (2013). CSF p-Tau levels in the prediction of Alzheimer's disease. Biol. Open 2, 1119-1124. doi: 10.1242/bio.20135447

Klein, J. A., and Ackerman, S. L. (2003). Oxidative stress, cell cycle, and neurodegeneration. J. Clin. Invest. 111, 785-793. doi: 10.1172/jci18182

Kruman, I. I. (2004). Why do neurons enter the cell cycle? Cell Cycle 3, 769-773.

Lee, E. S., Lee, J. O., Lee, S. K., Kim, J. H., Jung, J. H., Keum, B., et al. (2009). Caffeic acid phenethyl ester accumulates beta-catenin through GSK-3beta and participates in proliferation through mTOR in C2C12 cells. Life Sci. 84, 755759. doi: 10.1016/j.lfs.2009.03.004

Levy-Lahad, E., Wasco, W., Poorkaj, P., Romano, D. M., Oshima, J., Pettingell, W. H., et al. (1995). Candidate gene for the chromosome 1 familial Alzheimer's disease locus. Science 269, 973-977.

Li, J. M., Liu, C., Hu, X., Cai, Y., Ma, C., Luo, X. G., et al. (2014). Inverse correlation between Alzheimer's disease and cancer: implication for a strong impact of regenerative propensity on neurodegeneration? BMC Neurol. 14:211. doi: 10.1186/s12883-014-0211-2

Li, L., Zhang, S., Zhang, X., Li, T., Tang, Y., Liu, H., et al. (2013). Autophagy enhancer carbamazepine alleviates memory deficits and cerebral amyloid-beta pathology in a mouse model of Alzheimer's disease. Curr. Alzheimer Res. 10, 433-441.

Lin, A., Yao, J., Zhuang, L., Wang, D., Han, J., Lam, E. W., et al. (2014). The FoxOBNIP3 axis exerts a unique regulation of mTORC1 and cell survival under energy stress. Oncogene 33, 3183-3194. doi: 10.1038/onc.2013.273

Liu, C., and Zong, H. (2012). Developmental origins of brain tumors. Curr. Opin Neurobiol. 22, 844-849. doi: 10.1016/j.conb.2012.04.012

Liu, D. X., and Greene, L. A. (2001). Neuronal apoptosis at the G1/S cell cycle checkpoint. Cell Tissue Res. 305, 217-228.
Liu, F., Su, Y., Li, B., Zhou, Y., Ryder, J., Gonzalez-Dewhitt, P., et al. (2003). Regulation of amyloid precursor protein (APP) phosphorylation and processing by $\mathrm{p} 35 / \mathrm{Cdk} 5$ and $\mathrm{p} 25 / \mathrm{Cdk} 5$. FEBS Lett. 547, 193-196.

Liu, P., Cheng, H., Roberts, T. M., and Zhao, J. J. (2009). Targeting the phosphoinositide 3-kinase pathway in cancer. Nat. Rev. Drug Discov. 8, 627644. doi: $10.1038 / \mathrm{nrd} 2926$

Lopes, J. P., Oliveira, C. R., and Agostinho, P. (2009). Cell cycle re-entry in Alzheimer's disease: a major neuropathological characteristic? Curr. Alzheimer Res. 6, 205-212.

Ma, Q., Qiang, J., Gu, P., Wang, Y., Geng, Y., and Wang, M. (2011). Age-related autophagy alterations in the brain of senescence accelerated mouse prone 8 (SAMP8) mice. Exp. Gerontol. 46, 533-541. doi: 10.1016/j.exger.2011.02.006

Maccioni, R. B., Munoz, J. P., and Barbeito, L. (2001). The molecular bases of Alzheimer's disease and other neurodegenerative disorders. Arch. Med. Res. 32, 367-381.

Majd, S., Power, J. H., and Grantham, H. J. (2015). Neuronal response in Alzheimer's and Parkinson's disease: the effect of toxic proteins on intracellular pathways. BMC Neurosci. 16:69. doi: 10.1186/s12868-015-0211-1

Majd, S., and Power, J. H. T. (2018). Oxidative stress and decreased mitochondrial superoxide dismutase 2 and peroxiredoxins 1 and 4 based mechanism of concurrent activation of AMPK and mTOR in Alzheimer's Disease. Curr. Alzheimer Res. 15, 764-776. doi: 10.2174/1567205015666180223093020

Majd, S., Zarifkar, A., Rastegar, K., and Takhshid, M. A. (2008). Different fibrillar Abeta 1-42 concentrations induce adult hippocampal neurons to reenter various phases of the cell cycle. Brain Res. 1218, 224-229. doi: 10.1016/j. brainres.2008.04.050

McShea, A., Lee, H. G., Petersen, R. B., Casadesus, G., Vincent, I., Linford, N. J., et al. (2007). Neuronal cell cycle re-entry mediates Alzheimer disease-type changes. Biochim. Biophys. Acta 1772, 467-472. doi: 10.1016/j.bbadis.2006. 09.010

Mitchell, T. W., Mufson, E. J., Schneider, J. A., Cochran, E. J., Nissanov, J., Han, L. Y., et al. (2002). Parahippocampal tau pathology in healthy aging, mild cognitive impairment, and early Alzheimer's disease. Ann. Neurol. 51, 182-189.

Moh, C., Kubiak, J. Z., Bajic, V. P., Zhu, X., Smith, M. A., and Lee, H. G. (2011). Cell cycle deregulation in the neurons of Alzheimer's disease. Results Probl. Cell Differ. 53, 565-576. doi: 10.1007/978-3-642-19065-0_23

Moreira, P. I., Carvalho, C., Zhu, X., Smith, M. A., and Perry, G. (2010). Mitochondrial dysfunction is a trigger of Alzheimer's disease pathophysiology. Biochim. Biophys. Acta 1802, 2-10. doi: 10.1016/j.bbadis.2009.10.006

Morgan, T. M., Koreckij, T. D., and Corey, E. (2009). Targeted therapy for advanced prostate cancer: inhibition of the PI3K/Akt/mTOR pathway. Curr. Cancer Drug Targets 9, 237-249.

Morgen, K., and Frolich, L. (2015). The metabolism hypothesis of Alzheimer's disease: from the concept of central insulin resistance and associated consequences to insulin therapy. J. Neural Transm. 122, 499-504. doi: 10.1007/ s00702-015-1377-5

Moschetta, M., Reale, A., Marasco, C., Vacca, A., and Carratu, M. R. (2014). Therapeutic targeting of the mTOR-signalling pathway in cancer: benefits and limitations. Br. J. Pharmacol. 171, 3801-3813. doi: 10.1111/bph.12749

Musicco, M., Adorni, F., Di Santo, S., Prinelli, F., Pettenati, C., Caltagirone, C., et al. (2013). Inverse occurrence of cancer and Alzheimer disease: a population-based incidence study. Neurology 81, 322-328. doi: 10.1212/WNL.0b013e31829c5ec1

Nagy, Z. (2000). Cell cycle regulatory failure in neurones: causes and consequences. Neurobiol. Aging 21, 761-769.

Nagy, Z., Esiri, M. M., and Smith, A. D. (1998). The cell division cycle and the pathophysiology of Alzheimer's disease. Neuroscience 87, 731-739.

Nigg, E. A. (2001). Mitotic kinases as regulators of cell division and its checkpoints. Nat. Rev. Mol. Cell Biol. 2, 21-32. doi: 10.1038/35048096

Norambuena, A., Wallrabe, H., Mcmahon, L., Silva, A., Swanson, E., Khan, S. S., et al. (2017). mTOR and neuronal cell cycle reentry: How impaired brain insulin signaling promotes Alzheimer's disease. Alzheimers Dement. 13, 152-167. doi: 10.1016/j.jalz.2016.08.015

O'Neill, C. (2013). PI3-kinase/Akt/mTOR signaling: impaired on/off switches in aging, cognitive decline and Alzheimer's disease. Exp. Gerontol. 48, 647-653. doi: 10.1016/j.exger.2013.02.025

Pei, J. J., and Hugon, J. (2008). mTOR-dependent signalling in Alzheimer's disease. J. Cell Mol. Med. 12, 2525-2532. doi: 10.1111/j.1582-4934.2008.00509.x 
Pierce, A., Podlutskaya, N., Halloran, J. J., Hussong, S. A., Lin, P. Y., Burbank, R., et al. (2013). Over-expression of heat shock factor 1 phenocopies the effect of chronic inhibition of TOR by rapamycin and is sufficient to ameliorate Alzheimer's-like deficits in mice modeling the disease. J. Neurochem. 124, 880-893. doi: 10.1111/jnc. 12080

Planas-Silva, M. D., and Weinberg, R. A. (1997). The restriction point and control of cell proliferation. Curr. Opin Cell Biol. 9, 768-772.

Populo, H., Lopes, J. M., and Soares, P. (2012). The mTOR signalling pathway in human cancer. Int. J. Mol. Sci. 13, 1886-1918. doi: 10.3390/ijms1302 1886

Porta, C., Paglino, C., and Mosca, A. (2014). Targeting PI3K/Akt/mTOR Signaling in Cancer. Front. Oncol. 4:64. doi: 10.3389/fonc.2014.00064

Price, J. L., and Morris, J. C. (1999). Tangles and plaques in nondemented aging and "preclinical". Alzheimer's disease. Ann. Neurol. 45, 358-368.

Ramsden, M., Kotilinek, L., Forster, C., Paulson, J., Mcgowan, E., Santacruz, K., et al. (2005). Age-dependent neurofibrillary tangle formation, neuron loss, and memory impairment in a mouse model of human tauopathy (P301L). J. Neurosci. 25, 10637-10647. doi: 10.1523/jneurosci.3279-05.2005

Ravikumar, B., Duden, R., and Rubinsztein, D. C. (2002). Aggregate-prone proteins with polyglutamine and polyalanine expansions are degraded by autophagy. Hum. Mol. Genet. 11, 1107-1117.

Rodon, J., Dienstmann, R., Serra, V., and Tabernero, J. (2013). Development of PI3K inhibitors: lessons learned from early clinical trials. Nat. Rev. Clin. Oncol. 10, 143-153. doi: 10.1038/nrclinonc.2013.10

Roe, C. M., Fitzpatrick, A. L., Xiong, C., Sieh, W., Kuller, L., Miller, J. P., et al. (2010). Cancer linked to Alzheimer disease but not vascular dementia. Neurology 74, 106-112. doi: 10.1212/WNL.0b013e3181c91873

Rogaeva, E., Kawarai, T., and George-Hyslop, P. S. (2006). Genetic complexity of Alzheimer's disease: successes and challenges. J. Alzheimers Dis. 9, 381-387.

Romero, J. P., Benito-Leon, J., Louis, E. D., and Bermejo-Pareja, F. (2014). Alzheimer's disease is associated with decreased risk of cancer-specific mortality: a prospective study (NEDICES). J. Alzheimers Dis. 40, 465-473. doi: $10.3233 /$ jad- 132048

Sanchez-Valle, J., Tejero, H., Ibanez, K., Portero, J. L., Krallinger, M., AlShahrour, F., et al. (2017). A molecular hypothesis to explain direct and inverse co-morbidities between Alzheimer's Disease, Glioblastoma and Lung cancer. Sci. Rep. 7:4474. doi: 10.1038/s41598-017-04400-6

Santo, E. E., Stroeken, P., Sluis, P. V., Koster, J., Versteeg, R., and Westerhout, E. M. (2013). FOXO3a is a major target of inactivation by PI3K/AKT signaling in aggressive neuroblastoma. Cancer Res. 73, 2189-2198. doi: 10.1158/0008-5472. can-12-3767

Sherrington, R., Rogaev, E. I., Liang, Y., Rogaeva, E. A., Levesque, G., Ikeda, M., et al. (1995). Cloning of a gene bearing missense mutations in earlyonset familial Alzheimer's disease. Nature 375, 754-760. doi: 10.1038/3757 $54 \mathrm{a} 0$

Shi, H. B., Tang, B., Liu, Y. W., Wang, X. F., and Chen, G. J. (2015). Alzheimer disease and cancer risk: a meta-analysis. J. Cancer Res. Clin. Oncol. 141, 485-494. doi: 10.1007/s00432-014-1773-5

Silva, J. M., Rodrigues, S., Sampaio-Marques, B., Gomes, P., Neves-Carvalho, A., Dioli, C., et al. (2018). Dysregulation of autophagy and stress granule-related proteins in stress-driven Tau pathology. Cell Death Differ doi: 10.1038/s41418018-0217-1 [Epub ahead of print].

Slomovitz, B. M., and Coleman, R. L. (2012). The PI3K/AKT/mTOR pathway as a therapeutic target in endometrial cancer. Clin. Cancer Res. 18, 5856-5864. doi: 10.1158/1078-0432.ccr-12-0662

Sotiropoulos, I., Catania, C., Pinto, L. G., Silva, R., Pollerberg, G. E., Takashima, A., et al. (2011). Stress acts cumulatively to precipitate Alzheimer's disease-like tau pathology and cognitive deficits. J. Neurosci. 31, 7840-7847. doi: 10.1523/ jneurosci.0730-11.2011

Spencer, B., Potkar, R., Trejo, M., Rockenstein, E., Patrick, C., Gindi, R., et al. (2009). Beclin 1 gene transfer activates autophagy and ameliorates the neurodegenerative pathology in alpha-synuclein models of Parkinson's and Lewy body diseases. J. Neurosci. 29, 13578-13588. doi: 10.1523/jneurosci.439009.2009

Spilman, P., Podlutskaya, N., Hart, M. J., Debnath, J., Gorostiza, O., Bredesen, D., et al. (2010). Inhibition of mTOR by rapamycin abolishes cognitive deficits and reduces amyloid-beta levels in a mouse model of Alzheimer's disease. PLoS One 5:e9979. doi: 10.1371/journal.pone.0009979

Statz, C. M., Patterson, S. E., and Mockus, S. M. (2017). mTOR inhibitors in castration-resistant prostate cancer: a systematic review. Target Oncol. 12, 47-59. doi: 10.1007/s11523-016-0453-6

Stumpf, C. R., Moreno, M. V., Olshen, A. B., Taylor, B. S., and Ruggero, D. (2013). The translational landscape of the mammalian cell cycle. Mol. Cell 52, 574-582. doi: 10.1016/j.molcel.2013.09.018

Sun, Y., Shi, Z., Lian, H., and Cai, P. (2016). Energy metabolic dysfunction as a carcinogenic factor in cancer cells. Clin. Transl. Med. 5:14. doi: 10.1186/s40169016-0094-5

Talbot, K., Wang, H. Y., Kazi, H., Han, L. Y., Bakshi, K. P., Stucky, A., et al. (2012). Demonstrated brain insulin resistance in Alzheimer's disease patients is associated with IGF-1 resistance, IRS-1 dysregulation, and cognitive decline. J. Clin. Invest. 122, 1316-1338. doi: 10.1172/jci5 9903

Tiwari, V. K., Burger, L., Nikoletopoulou, V., Deogracias, R., Thakurela, S., Wirbelauer, C., et al. (2012). Target genes of Topoisomerase IIbeta regulate neuronal survival and are defined by their chromatin state. Proc. Natl. Acad. Sci. U.S.A. 109, E934-E943. doi: 10.1073/pnas.111979 8109

Vadlakonda, L., Pasupuleti, M., and Pallu, R. (2013). Role of PI3K-AKT-mTOR and Wnt Signaling Pathways in Transition of G1-S Phase of Cell Cycle in Cancer Cells. Front. Oncol. 3:85. doi: 10.3389/fonc.2013.00085

Visconti, R., Della Monica, R., and Grieco, D. (2016). Cell cycle checkpoint in cancer: a therapeutically targetable double-edged sword. J. Exp. Clin. Cancer Res. 35:153. doi: 10.1186/s13046-016-0433-9

Webber, K. M., Raina, A. K., Marlatt, M. W., Zhu, X., Prat, M. I., Morelli, L., et al. (2005). The cell cycle in Alzheimer disease: a unique target for neuropharmacology. Mech. Ageing Dev. 126, 1019-1025. doi: 10.1016/j.mad. 2005.03.024

Wen, Y., Yang, S., Liu, R., Brun-Zinkernagel, A. M., Koulen, P., and Simpkins, J. W. (2004). Transient cerebral ischemia induces aberrant neuronal cell cycle re-entry and Alzheimer's disease-like tauopathy in female rats. J. Biol. Chem. 279, 22684-22692. doi: 10.1074/jbc.M311768200

White, M. C., Holman, D. M., Boehm, J. E., Peipins, L. A., Grossman, M., and Henley, S. J. (2014). Age and cancer risk: a potentially modifiable relationship. Am. J. Prev. Med. 46, S7-S15. doi: 10.1016/j.amepre.2013. 10.029

Williams, G. H., and Stoeber, K. (2012). The cell cycle and cancer. J. Pathol. 226, 352-364. doi: 10.1002/path.3022

$\mathrm{Xu}$, J., Ji, J., and Yan, X. H. (2012). Cross-talk between AMPK and mTOR in regulating energy balance. Crit. Rev. Food Sci. Nutr. 52, 373-381. doi: 10.1080/ 10408398.2010.500245

Yang, D., Li, L., Liu, H., Wu, L., Luo, Z., Li, H., et al. (2013). Induction of autophagy and senescence by knockdown of ROC1 E3 ubiquitin ligase to suppress the growth of liver cancer cells. Cell Death Differ. 20, 235-247. doi: 10.1038/cdd. 2012.113

Yang, J. H., Siroky, M. B., Yalla, S. V., and Azadzoi, K. M. (2017). Mitochondrial stress and activation of PI3K and Akt survival pathway in bladder ischemia. Res. Rep. Urol. 9, 93-100. doi: 10.2147/rru.s132082

Yang, Y., Geldmacher, D. S., and Herrup, K. (2001). DNA replication precedes neuronal cell death in Alzheimer's disease. J. Neurosci. 21, 2661-2668.

Yang, Y., and Herrup, K. (2007). Cell division in the CNS: protective response or lethal event in post-mitotic neurons? Biochim. Biophys. Acta 1772, 457-466. doi: 10.1016/j.bbadis.2006.10.002

Yang, Y., Mufson, E. J., and Herrup, K. (2003). Neuronal cell death is preceded by cell cycle events at all stages of Alzheimer's disease. J. Neurosci. 23, 2557-2563.

Yu, J. S., and Cui, W. (2016). Proliferation, survival and metabolism: the role of PI3K/AKT/mTOR signalling in pluripotency and cell fate determination. Development 143, 3050-3060. doi: 10.1242/dev.137075

Zhang, Z., Zhang, Z., Wang, H., Zhang, G., Hu, D., Xiong, J., et al. (2014). Proliferating cell nuclear antigen binds DNA polymerase-beta and mediates 1-methyl-4-phenylpyridinium-induced neuronal death. PLoS One 9:e106669. doi: 10.1371/journal.pone.0106669 
Zhao, Y., Hu, X., Liu, Y., Dong, S., Wen, Z., He, W., et al. (2017). ROS signaling under metabolic stress: cross-talk between AMPK and AKT pathway. Mol. Cancer 16:79. doi: 10.1186/s12943-017-0648-1

Zhou, H., and Huang, S. (2011). Role of mTOR signaling in tumor cell motility, invasion and metastasis. Curr. Protein Pept Sci. 12, $30-42$.

Zhu, X., Mcshea, A., Harris, P. L., Raina, A. K., Castellani, R. J., Funk, J. O., et al. (2004). Elevated expression of a regulator of the G2/M phase of the cell cycle, neuronal CIP-1-associated regulator of cyclin B, in Alzheimer's disease. J. Neurosci. Res. 75, 698-703. doi: 10.1002/jnr.20028
Conflict of Interest Statement: The authors declare that the research was conducted in the absence of any commercial or financial relationships that could be construed as a potential conflict of interest.

Copyright $\odot 2019$ Majd, Power and Majd. This is an open-access article distributed under the terms of the Creative Commons Attribution License (CC BY). The use, distribution or reproduction in other forums is permitted, provided the original author(s) and the copyright owner(s) are credited and that the original publication in this journal is cited, in accordance with accepted academic practice. No use, distribution or reproduction is permitted which does not comply with these terms. 